\title{
Barriers to sustainable consumption attenuated by foreign language use
}

\author{
Janet Geipel ${ }^{1 \star}$, Constantinos Hadjichristidis ${ }^{2,3}$ and Anne-Kathrin Klesse ${ }^{4}$
}

\begin{abstract}
The adoption of certain innovative products, such as recycled water, artificial meat and insect-based food, could help promote sustainability. However, the disgust these products elicit acts as a barrier to their consumption. Here, we show that describing such products in a foreign language attenuates the disgust these products trigger and heightens their intended as well as actual consumption.
\end{abstract}

One goal of the United Nations' 2030 Agenda for Sustainable Development concerns sustainable consumption. The adoption of innovative products, such as recycled water, artificial meat and insect-based food, would move us closer to achieving this goal. Recycled water can improve the lives of four billion people who are facing water shortages ${ }^{1}$. Similarly, insect-based food presents an environmentally friendly alternative to beef ${ }^{2}$. Yet, many citizens refuse to adopt such products. When we polled 299 Mechanical Turkers on whether they would consume artificial meat, recycled water and insect-based food (Yes/No/Unsure), on average, for each product, only $33.2 \%$ responded Yes.

The main barrier to the adoption of these products is the disgust they elicit. Although recycled water is technically clean, in people's minds it is dirty because it was once in contact with a disgusting entity ${ }^{3}$. Similarly, surveys on artificial meat and insectbased food link refusal to adopt these products to feelings of disgust ${ }^{4,5}$. This raises the question: how can we nudge citizens to consume such products? Here we explore a language intervention: describing such products in a foreign language. By 'foreign language' we mean a language that an individual has learned in a formal, academic context outside of the environment where it is used as a native language ${ }^{6}$.

Our motivation comes from research showing that foreignlanguage use can attenuate negative feelings and suppress emotionbased judgments and decisions $s^{6,7}$. Marketing slogans-such as "parents who use drugs have kids who use drugs" - are rated as less emotional when read in a foreign versus native language ${ }^{8}$. Similarly, childhood reprimands-such as "shame on you"-trigger reduced skin conductance reactions in a foreign language ${ }^{9}$. Foreign-language use also reduces framing effects ${ }^{10,11}$, which are thought to be driven by loss aversion, and increases the moral endorsement of actions, such as eating one's dead pet ${ }^{12}$, which people typically condemn due to the disgust they elicit ${ }^{13}$.

Building on this research, we hypothesized that describing sustainable but aversive products in a foreign language would increase willingness to consume by reducing feelings of disgust elicited when described in the native language. Although previous research suggests that foreign language use dampens emotions, there exists little evidence to link foreign language effects in judgment and decision making to emotion attenuation ${ }^{14}$. Below we present the results of four experiments that investigated these hypotheses in the context of sustainable consumption.

Experiments 1-3 examined intended product consumption. Participants received a description of an aversive product-artificial meat (Experiment 1), recycled water (Experiment 2) or insectbased cookies (Experiment 3)-either in their native or a foreign language (see Supplementary Table 1), and were asked whether they would consume it (Yes/Unsure/No; treated as an ordinal scale). As predicted, foreign-language use increased willingness to consume these products across all three experiments (see Fig. 1; artificial meat, Mann-Whitney $U$ test $(U)=3,220.5, P=0.033$, standardized test statistic $(z)=2.13$, effect size of $U(r)=0.18$; recycled water, $U=6,057.0, P=0.036, z=2.09, r=0.15$; and insect-based cookies, $U=2,511.0, P=0.017, z=2.38, r=0.21)$.

Experiment 3 sought evidence for the underlying mechanism. Following the willingness-to-consume question, participants rated their feelings of disgust towards the insect-based cookies $(1=$ not at all disgusting to $9=$ very disgusting; Supplementary Fig. 1), which we tested as a possible mediator of the relation between language and willingness-to-consume. We calculated bias-corrected $95 \%$ confidence intervals using bootstrapping with 1,000 resamples ${ }^{15}$. The relationship between language and consumption of insectbased cookies $(b=0.37, t(126)=2.43, P=0.016,95 \%$ confidence interval $(0.0647,0.6303))$ became nonsignificant once feelings of disgust were taken into account $(b=0.13, t(126)=1.37, P=0.173$, $95 \%$ confidence interval $(-0.0577,0.3179))$, while the indirect effect of foreign language through feelings of disgust was significant $(b=0.22,95 \%$ confidence interval $(0.0021,0.4054))$. Thus, feelings of disgust mediated the association between language and willingness to consume (Fig. 2).

Experiment 4 examined actual consumption. Following a description of recycled water in either their native or foreign language, participants were provided with a cup that supposedly contained recycled water (participants were later debriefed that the cup contained bottled water), and were instructed to drink as much as they wished. We predicted higher consumption in the foreign language condition but mostly for individuals who were not too thirsty-thirsty individuals are likely to consume water irrespective of the language condition they were assigned ${ }^{16}$. A preliminary analysis revealed that most participants drank water (native language: $94.8 \%$ versus foreign language: $98.9 \% ; \chi^{2}(1, N=186)=2.42$, $P=0.12$ ), perhaps because Experiment 4 was preceded by a study that involved working out on a stepper.

We then tested our main hypothesis by conducting a multiple regression analysis. As an indicator of thirstiness, we used responses to the question: "When was the last time you drank water/soda/juice before the experiment?" To avoid multicollinearity

'Department of Psychology, University of Chicago, Chicago, IL, USA. ${ }^{2}$ Department of Economics and Management, University of Trento, Trento, Italy. ${ }^{3}$ Centre for Decision Research, Leeds University Business School, University of Leeds, Leeds, UK. ${ }^{4}$ Department of Marketing Management, Erasmus University Rotterdam, Rotterdam, The Netherlands. *e-mail: jgeipel@uchicago.edu 

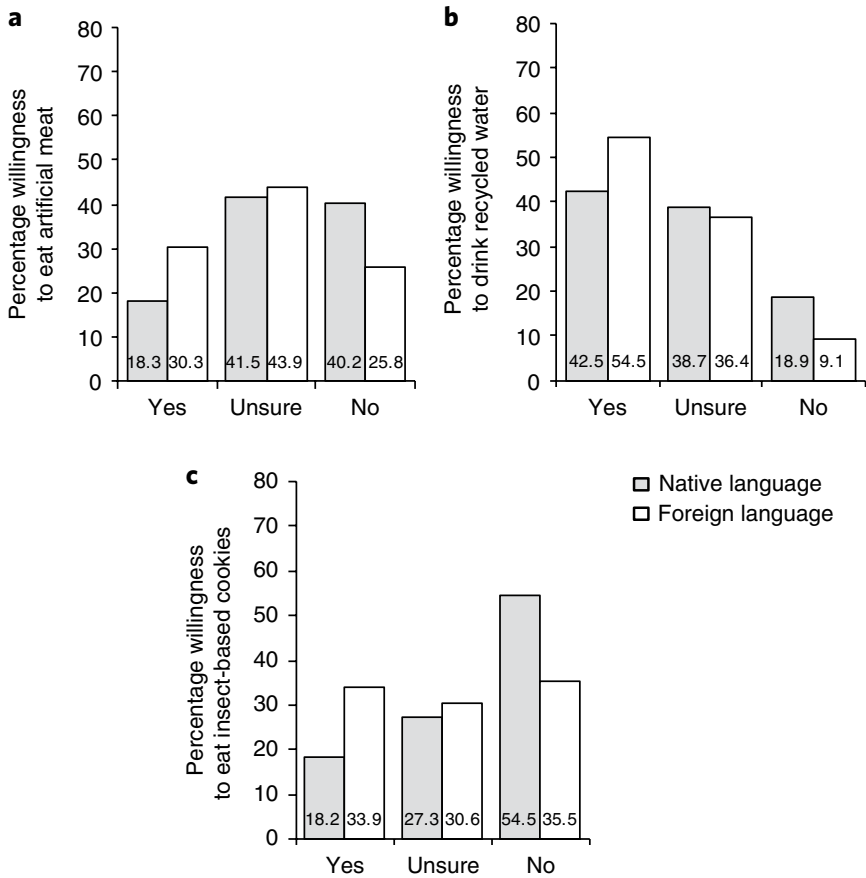

Fig. 1 | Language influences willingness to consume. a-c, Percentages of Yes/Unsure/No choices for willingness to eat artificial meat (a, Experiment 1), willingness to drink recycled water (b, Experiment 2) and willingness to eat insect-based cookies (c, Experiment 3), by language condition.

with the interaction term, we first centred the variables and then conducted a regression analysis with language and thirstiness as the predictors and water consumption as the outcome variable. The predictors accounted for a significant amount of variance in water consumption $\left(R^{2}=0.069, F(2,183)=6.83, P=0.001\right.$, Cohen's $\left.f^{2}=0.07\right)$. Thirstiness significantly predicted water consumption $(\beta=0.26, t(183)=3.70, P<0.001)$, while language did not $(\beta=0.02, t(183)=0.24, P=0.807)$. Adding the interaction term (language $\times$ thirstiness) to the regression model, accounted for a significant proportion of the remaining variance $\left(R^{2}=0.093, \Delta\right.$ $R^{2}=0.024, \Delta F(1,182)=4.72, P=0.031, \beta=-0.15, t(182)=-2.17$, $P=0.031$, Cohen's $f^{2}=0.10$ ).

The interaction was scrutinized with a linear regression analysis using the Modprobe procedure ${ }^{17}$. We applied the Johnson-Neyman technique, which identifies regions in the range of the moderator variable (thirstiness) where the effect of the predictor (language) on the outcome (water consumption) is statistically significant and non-significant. In line with our prediction, at low levels of thirstiness $(<1.60)$ foreign language marginally increased recycled water consumption $(t(182)=1.92, P=0.057)$, but as thirstiness rises language has no influence on water consumption (Supplementary Fig. 2, Supplementary Table 2).

The present research shows that describing aversive but sustainable products in a foreign language increases intended and actual consumption by attenuating the disgust these products trigger in the native language. These findings underscore the interconnectedness between language, thought and behaviour. A verbal description that signals avoidance in the native language indicates a lesser threat in a foreign language. Our results confirm and extend those of previous studies showing that foreign language can modify judgment and choice ${ }^{10-12}$. They add that it can influence intention as well as behaviour, and, importantly, attenuate barriers to sustainability.

What drives the reduced emotionality of a foreign language? According to the emotional contexts of learning hypothesis ${ }^{7}$, a language gains emotionality by virtue of being learned and used in

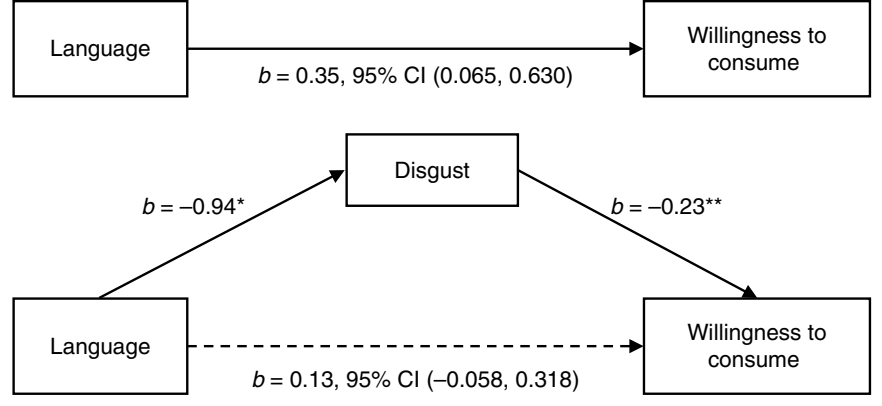

Fig. 2 | Language influences willingness to consume through feelings of disgust. Unstandardized regression coefficients ( $b$ ) and bootstrap confidence intervals for the association between language and willingness to consume insect-based cookies as mediated by feelings of disgust (Experiment 3). ${ }^{\star} P=0.047,{ }^{\star \star} P=0.001$.

emotional contexts. A foreign language lacks emotionality because it is used in non-emotional contexts such as classrooms. The assumption is that experiences and associated emotions are stored together with the linguistic context in which they occur, and are thus more easily accessed when the same language is used at retrieval ${ }^{18}$.

The present intervention is actionable because most people live in multilingual societies where foreign-language use is commonplace. For less-proficient foreign-language users or monolinguals, the intervention could instead target product labelling. Perhaps Singapore's Public Utilities Board had good reasons for promoting recycled water by using the English label 'NEWater' rather than its translation equivalent in one of Singapore's ethnic languages. Alternatively, the intervention may use a native-language label that minimizes the elicitation of disgust. A field study has found that farmers and consumers are more willing to use purified wastewater when it is described as 'recycled water' rather than 'treated wastewater' ${ }^{\prime \prime}$.

\section{Methods}

Participants were foreign-language users. Assignment to language conditions was randomized. We screened out non-native speakers as well as participants assigned to the foreign language condition who were either native speakers of the foreign language, lived for more than a year in a country where that language is spoken, or provided inadequate translations (Supplementary Table 3). Materials were written in English and then translated and back-translated to the target languages ${ }^{20}$.

The task order was: willingness-to-consume question; secondary measure (disgust, Experiment 3; thirstiness, Experiment 4); control measures (Supplementary Method; Supplementary Tables 4-6); translations; and demographic details. Participants assigned to the foreign language condition were asked to translate either the entire product description or some key terms (Supplementary Table 7), and to report age-of-acquisition and proficiency in the foreign language (Supplementary Table 8). Control and demographic questions were presented in the native language.

Experiment 1 was an online survey with 161 participants (78\% females; mean age $\left.\left(M_{\text {age }}\right)=27.1\right) ; 79$ in the foreign-language (English; 76\% females), and 82 in the native-language condition (German; $79 \%$ females). The target question was: "Would you eat artificial meat?"

Experiment 2 was a paper-and-pencil classroom study with 212 volunteers from Italian universities $\left(66 \%\right.$ females; $\left.M_{\text {age }}=21.3\right)$; 106 in the foreign-language (English or German; 64\% females), and 106 in the native-language condition (Italian; $67 \%$ females). The target question was: "Would you be willing to drink certified-safe recycled water?" (for additional results see Supplementary Table 9)

Experiment 3 was an online survey with 141 volunteers from social media (77\% females; $M_{\text {age }}=27.9$ ); 71 in the foreign-language (English; $79 \%$ females), and 70 in the native-language condition (German; 76\% females). Following the product description, participants were asked: "Would you eat mealworm cookies?" (Yes/Unsure/No) and then to rate the extent to which they agree/disagree with the phrase "The thought of eating a mealworm cookie is disgusting" $(1=$ not at all disgusting; $9=$ very disgusting).

Experiment 4 was a computer-based lab study involving 201 participants from a Dutch university (44\% females; $M_{\text {age }}=20.9$ ); 99 in the foreign-language (English; $43 \%$ females) and 102 in the native-language condition (Dutch; $43 \%$ females). 
Following the product's description, participants read: "We would now like to ask you to taste the recycled water. Please inform the research assistant once you have read the instructions and can proceed with the taste test." The research assistant, who was blind to the purpose of the experiment, then brought them a cup of water. Participants then proceeded with the survey on the computer: "Did you receive the water? If yes, you can now continue" and then: "Please drink as much recycled water as you want. Of course, you are not obliged to drink it." Thirstiness was gauged by: "When was the last time you drank water/soda/juice before the experiment?" ( $1=$ right before; $2=30$ minutes before; $3=$ An hour before; $4=$ More than an hour before); "When you were asked to drink the recycled water, how thirsty were you?" ( $1=$ not at all thirsty to $7=$ extremely thirsty).

Data availability. Data are included as Supplementary Data Sets.

Received: 2 July 2017; Accepted: 28 November 2017; Published online: 8 January 2018

\section{References}

1. Santiago, J. 4 billion people face water shortages, scientists find. World Economic Forum (17 February 2016); https://www.weforum.org/agenda/2016/02/4-billionpeople-face-severe-water-scarcity-at-least-for-one-month-every-year

2. Goodyear, D. Grub: eating bugs to save the planet. The New Yorker (15 August 2011); http://www.newyorker.com/magazine/2011/08/15/grub

3. Rozin, P., Haddad, B., Nemeroff, C. \& Slovic, P. Judgm. Decis. Mak. 10, 50-63 (2015).

4. Verbeke, W. et al. Meat Sci. 102, 49-58 (2015).

5. Verbeke, W. Food Qual. Prefer. 39, 147-155 (2015).

6. Pavlenko, A. Int. J. Psychol. 47, 405-428 (2012).

7. Caldwell-Harris, C. Curr. Dir. Psychol. Sci. 24, 214-219 (2015).

8. Puntoni, S., de Langhe, B. \& van Osselaer, S. J. J. Consum. Res. 35, 1012-1025 (2009).

9. Harris, C., Aycicegi, A. \& Gleason, J. Appl. Psycholinguist. 24, 561-571 (2003).

10. Keysar, B., Hayakawa, S. L. \& An, S. Psychol. Sci. 23, 661-668 (2012).

11. Costa, A. et al. PLoS ONE 9, e94842 (2014).

12. Geipel, J., Hadjichristidis, C. \& Surian, L. J. Exp. Soc. Psychol. 59, 8-17 (2015).

13. Haidt, J. Psychol. Rev. 108, 814-834 (2001).
14. Hadjichristidis, C., Geipel, J. \& Savadori, L. J. Exp. Psychol. Appl. 21, 117-129 (2015).

15. Preacher, K. J. \& Hayes, A. F. Behav. Res. Methods 40, 879-891 (2008). 16. Maslow, A. H. Psychol. Rev. 50, 370-396 (1943).

17. Hayes, A. F. \& Matthes, J. Behav. Res. Methods. 41, 924-936 (2009).

18. Marian, V. \& Neisser, U. J. Exp. Psychol. Gen. 129, 361-368 (2000).

19. Menegaki, A. N., Mellon, R. C., Vrentzou, A., Koumakis, G. \& Tsagarakis, K. P. J. Econ. Psychol. 30, 285-292 (2009).

20. Brislin, R. W. J. Cross-Cult. Psychol. 1, 185-216 (1970).

\section{Acknowledgements}

We thank S. Puntoni, J. Levav and L. Burnett for valuable comments on preliminary versions of this manuscript and J. Bekkers and J. Klesse for assisting with data collection. Financial support from the Netherlands Organization for Scientific Research (VENI grant 451-15-023 awarded to A.K.) is gratefully acknowledged.

\section{Author contributions}

J.G. and C.H. developed the study concept. All authors contributed to the study design. J.G. performed testing and data collection for Experiments 1-3 and A.K. coordinated data collection for Experiment 4. J.G. performed the data analysis and interpretation under the supervision of C.H. and A.K.; J.G. and C.H. drafted the manuscript, and A.K. provided critical revisions. All authors approved the final version of the manuscript for submission.

\section{Competing interests}

The authors declare no competing financial interests.

\section{Additional information}

Supplementary information is available for this paper at https://doi.org/10.1038/ s41893-017-0005-9.

Reprints and permissions information is available at www.nature.com/reprints. Correspondence and requests for materials should be addressed to J.G.

Publisher's note: Springer Nature remains neutral with regard to jurisdictional claims in published maps and institutional affiliations. 